\title{
Novos desafios para a capacitação de liderança de alto nível na gestão pública e governança em um mundo globalizante
}

O longo título deste trabalho abrange vasta gama de assuntos, o qual é uma iniciativa muito bem-vinda do Departamento de Assuntos Econômicos e Sociais da ONU e da Associação Internacional de Escolas e Institutos de Administração (IASIA). Para situar minha experiência, começarei com algumas palavras sobre minha história. Isso deve ajudar a explicar por que enfatizo alguns pontos e (aparentemente) ignoro outros.

Depois de obter Ph.D. em Ciência Política, com foco em desenvolvimento de políticas e assuntos internacionais, passei mais de 30 anos no governo canadense, tendo a maior parte do tempo trabalhado diretamente com ministros e primeiros-ministros. Isso me levou a refletir e a escrever sobre a informação que eles exigem para tomar decisões, como se pode assegurar que as consequiências de decisões específicas estão claras e, o que é particularmente difícil, se há modos de persuadir as pessoas eleitas a cada quatro ou cinco anos a pensar a longo prazo.

Por muito tempo desse período, o Canadá teve como primeiro-ministro Pierre Trudeau, que entendia que as verdadeiras grandes questões que afrontavam o Canadá e o mundo cada vez mais exigiam pensar adiante, agir antes de os problemas se tornarem esmagadores. Entretanto, com a convicção difundida de que os mercados eram a única maneira de garantir eficiência, havia e há uma tensão. O setor privado é regulado por balanços trimestrais (quaterly reports). Os governos não podem sê-lo, já que têm a responsabilidade de preparar seus países para o que está por vir nos anos à frente. Os níveis gerenciais têm de escutar tanto o povo quanto os seus superiores políticos cuja única preocupação é a reeleição, embora isso seja mais fácil dizer do que fazer.

Gordon S. Smith é $\mathrm{PhD}$ em ciência política pelo Massachusetts Institute of Technology (MIT), diretor do Centre for Global Studies e professor adjunto de ciência política na Universidade de Victoria, Canadá.

Contato: gordonssmith @ shaw.ca

Traduzido por Clifton M.

Teixeira 
Trudeau quis que os assuntos fossem debatidos de modo racional, estava interessado em como o seu governo poderia estabelecer prioridades e estar preparado para inovar. Eu o assessorei, por um período, em "mecanismo de questões governamentais" - em outras palavras, qual ministro deveria ser responsável por quais assuntos, como a estrutura departamental de governo deveria ser organizada e qual era o modo mais efetivo de organizar o processo decisório em nível ministerial. Essas são as prerrogativas do primeiro-ministro, embora implementá-las com leis possa vir a ser necessário. Ele quis assegurar que a organização do governo fosse responsiva aos desafios enfrentados.

Fui também responsável, durante parte desse tempo, por aconselhar sobre nomeações para altos cargos e sobre políticas de recursos humanos, geralmente para os níveis gerenciais do governo. Introduzimos um melhor planejamento de sucessão e de desenvolvimento de carreira. Tentamos correlacionar essa função ao surgimento de prioridades.

Trudeau acreditava que havia a necessidade de existir estrutura consciente de prioridades e que essas prioridades precisariam ser refletidas em decisões de gastos e prioridades legislativas. Embora não gostasse que o leitor tivesse a impressão de que tudo funcionou exatamente como deveria, alguns reais progressos foram alcançados. Houve sucesso em olhar a longo prazo, em trabalhar em assuntos que atravessam as barreiras dos departamentos e em conciliar assuntos domésticos e internacionais.

Em resumo, Pierre Trudeau entendeu que vivemos em um mundo cada vez mais interdependente, e isso é a base para minhas idéias sobre a capacitação de níveis gerenciais do governo.

Durante os últimos 15 anos de minha carreira no governo canadense, fui também ministro ou embaixador em posto de destaque no exterior. Como ministro de Relações Exteriores de 1994 a 1997, fui responsável pelo aconselhamento político e administrativo ( 8.000 pessoas, 1 bilhão de dólares americanos). Utilizarei bastante essa experiência no que se segue.

Os Ministérios de Relações Exteriores costumavam tratar de política externa. Relações com outros Estados podiam ser gerenciadas de maneira relativamente compartimentalizada, isto é, separadamente das políticas domésticas. Durante o último século, particularmente na última metade, os Ministérios de Relações Exteriores passaram, cada vez mais, a lidar com assuntos econômicos, aproximando-os, de forma nem sempre harmoniosa com outros ministérios, de assuntos domésticos.

O que descobri oito ou nove anos atrás, enquanto contemplava minha indicação como ministro de Relações Exteriores, foi o fato de que havia um tsunami (ou maremoto) de assuntos globais que estavam cada vez mais no centro das discussões internacionais, como mudanças climáticas, crime organizado transnacional e a propagação de doenças infecciosas, para citar três exemplos. Esses não eram os temas tradicionais de política externa. 
Nosso ministério não fora bem equipado para tratá-los. O aparato interdepartamental era fraco. No entanto, esses eram os assuntos que estavam cada vez mais na cabeça dos líderes. Criei uma secretaria principal focada nesses assuntos globais no Ministério das Relações Exteriores canadense e transferi recursos de objetivos mais tradicionais para mantê-la.

Também estava claro que a revolução da informação teria profundas implicações. O correio eletrônico e a internet iriam mudar a maneira como as pessoas se comunicam e acessam informações. Havia claros benefícios, mas também armadilhas. Não eram apenas novas tecnologias que estavam chegando. A forma organizacional hierárquica do ministério seria desafiada pelo efeito nivelador dessas mudanças tecnológicas. Os custos de investimento eram altos e, em muitos casos, os níveis gerenciais não estavam suficientemente familiarizados com a tecnologia para decidir o que era ou não necessário.

Fizemos grandes investimentos, mesmo em período de severos cortes orçamentários, nas tecnologias de informação e comunicação. E os benefícios agora estão sendo colhidos. Havia muitas objeções, mas perseveramos. Também refletimos sobre o que tudo isso significava para a maneira na qual negociávamos. Tentava imprimir liderança na administração da mudança.

\section{Definindo um "mundo globalizante"}

Há muitas definições para as palavras "globalizante", "globalização", "globalismo" e "globalista". Muito freqüentemente a globalização só é vista em termos econômicos. Enquanto a globalização econômica é uma realidade importante, ainda há muito mais por vir ${ }^{1}$.

Há, por exemplo, uma dimensão cultural muito importante. Muitos temem que a globalização econômica esteja conduzindo a uma homogeneização cultural, o que é realmente um perigo. Mas as novas tecnologias e a migração crescente também estão ajudando a desenvolver um forte potencial para novas redes e descobertas que podem facilitar a retenção cultural e o desenvolvimento. Há tanto dimensões negativas como positivas, assim como também há na globalização.

Com a globalização econômica, a chave é ter a capacidade para moldar a globalização de tal forma que as forças do mercado não determinem tudo. Retornarei a esta proposição mais adiante.

Questões ambientais críticas só podem obviamente ser tratadas em nível global. Os dois exemplos mais claros são a mudança climática e a biodiversidade. No entanto, alguns assuntos ambientais devem ser tratados em nível local, outros requerem compromisso nacional ou regional. 
Assuntos ligados à segurança não são novidade em nível global. A partir do desenvolvimento de armas nucleares e dos foguetes intercontinentais, ficamos, mais ou menos, acostumados a viver sob a espada de Dâmocles. Sabemos que nossa sobrevivência depende de eventos e decisões tomadas fora do nosso alcance.

A tecnologia está no cerne dessa interdependência crescente. As tecnologias da informação e da comunicação têm estado, evidentemente, no centro da globalização econômica. Estamos vivendo em tempo de revolução tecnológica, e não está claro quando, ou se, isso terminará.

As tecnologias genéticas levantam perguntas globais profundas propriedade intelectual, questões de igualdade, o potencial para enormes benefícios na área da saúde para países pobres, possíveis bons ou maus efeitos nos ecossistemas, questões ligadas à segurança e assim por diante. Tecnologias energéticas têm o potencial para lançar a atmosfera da Terra em um estado de desordem ou curá-la, envenenar pessoas pobres ou conduzi-las para fora da pobreza ${ }^{2}$.

A globalização sugere um mundo no qual a integração esteja ocorrendo. Um número crescente de pessoas - mas não significa todas - pode falar facilmente umas com as outras, ler ou assistir as mesmas notícias, investir nas mesmas companhias, escutar a mesma música e vertir-se com as mesmas marcas nas camisetas e nos tênis. Mas, ao mesmo tempo, o mundo está também se fragmentando, em parte precisamente como resposta à ameaça percebida de homogeneização - a necessidade por um sentimento de identidade com outros tidos como semelhantes. James Rosenau inventou uma palavra para esse aparentemente contraditório, mas de fato compreensível e consistente estado das coisas: fragmegration ${ }^{3,4}$.

Rosenau inventou outra palavra para descrever fenômeno igualmente importante - a dificuldade crescente de estabelecer limite entre as políticas internacional e doméstica. A palavra é "interméstica", que, de forma interessante, foi adotada como tema principal pelos organizadores do mais importante simpósio para altos executivos do serviço público canadense neste ano. Ninguém, até onde se saiba, fez objeção a essa caracterização do que está ocorrendo. No entanto, o desaparecimento do limite prévio relativamente claro entre as políticas doméstica e estrangeira tem implicações importantes para a gestão pública.

Esse mesmo cientista político norte-americano surgiu com uma terceira nova palavra para descrever mudanças nas políticas globais "multicêntrica". O velho mundo teve uma política estado-cêntrica. Os Estados eram virtualmente os únicos atores no cenário. Agora, e cada vez mais, há outros atores que não Estados, sendo os mais importantes as corporações transnacionais e as organizações não-governamentais internacionais. $\mathrm{O}$ mundo estado-cêntrico ainda existe, mas agora coexiste com um mundo multicêntrico com novos atores cujo perigo os Estados ignoram ${ }^{6}$. 
Em resumo, vivemos em um mundo no qual a interdependência está aumentando significativamente. Claro que ela é menos aparente para aqueles que nunca fizeram um telefonema, para aqueles sem eletricidade e para aqueles cuja subsistência (se houver) não dependa do desenvolvimento de meio mundo afora. Mas, para o resto do mundo, a complexidade crescente é uma principal conseqüência para aqueles encarregados da gestão pública.

\section{Governança}

Os governos não são mais os únicos atores na governança. Esses dias mais simples se foram. Os chamados "atores não estatais" agora têm crescente papel a desempenhar. Em algumas áreas, como a gestão da internet, eles assumiram papel dominante. Mais freqüentemente, os governos lidam com organizações internacionais, o setor privado e representantes da sociedade civil, e novas formas de governança estão surgindo. Atores não estatais estão cada vez mais sendo solicitados a fornecer serviços públicos, mas freqüentemente têm percebido que seus pontos de vista quanto às políticas não são solicitados ${ }^{7}$. Como foi pontuado pelo antigo ministro das Finanças canadense, Paul Martin, a governança retardou a globalização ${ }^{8}$. Martin, que liderou o grupo dos ministros das Finanças do G20, declarou, em encontros que nosso Centro organizou, que não há maior desafio do que gerenciar nossa crescente interdependência no mundo.

Governança em nível global é, certamente, muito mais complicada que em nível nacional. Neste último, as instituições ganham legitimidade por meio de processos políticos que envolvem os cidadãos. Realmente não há nada comparável em nível global. Assim como também não há "pacto social" que funcione em nível global, algo que em nível nacional é essencial para amortecer as mudanças.

Importante trabalho que está sendo agora terminado analisa como a governança global funciona de fato. O trabalho desbravador de P. J. Simmons e Chantal Jonge Oudraat é de destacável importância. O livro usa vários excelentes estudos de caso para produzir análise comparativa de, por exemplo, como as agendas são determinadas, como as negociações conduzem a acordos e como decisões são postas em vigor (se de fato são), de tal maneira que um profissional poderia diagnosticar qual seria o regime mais apropriado em outras áreas. Isso ajuda a responder perguntas sobre o que funciona e o que não funciona ${ }^{9}$.

Em tempos mais simples, política podia ser feita em nível de Estado na maioria dos assuntos diários. Hoje em dia, o que Wolfgang Reinicke chamou de "política pública global" é crescentemente requerida. O problema é, logicamente, que não há nada que se assemelhe a um governo 
global, e nem é provável que venha a haver a longo prazo. Há instituições internacionais - sendo as Nações Unidas a mais universal -, mas não há nada que se assemelhe a uma "democracia global", embora alguns tenham advogado o seu desenvolvimento ${ }^{10}$.

Outra evolução tem sido a proliferação de redes de muitos tipos. Elas podem ser exclusivamente de uso comercial, da sociedade civil, dos governos ou podem ser mistas. Elas podem envolver indivíduos como também instituições, ser mais ou menos formais e ter ou não tempo limitado. A tecnologia da informação facilita, obviamente, o crescimento de tais redes ${ }^{11}$.

\section{Democracia}

A democracia está cada vez mais difundida. As pessoas tornaramse mais acostumadas a eleger aqueles que tomam decisões que afetam as suas vidas. Elas acreditam que o que querem deveria determinar significativamente o que os seus "governantes" decidem. Se não o fizerem, as pessoas têm o poder de "se livrarem dos espertalhões". Esse fato ajuda a assegurar que os eleitos escutem os que os elegeram, ou sofram as conseqüiências se não o fizerem.

Isso não significa que a democracia sempre funcione bem ${ }^{12}$. Leva tempo para se desenvolverem regras apropriadas para os partidos políticos, regime para gerenciar a corrupção e sistema legal baseado na proteção dos direitos humanos, só para citar alguns exemplos do que é necessário. Instituições precisam crescer e uma cultura precisa ser desenvolvida. No entanto, expectativas se desenvolvem, a cultura muda e as instituições evoluem, mesmo que por meio de ajustes e recomeços.

As expectativas de organizações internacionais conseqüentemente cresceram, ainda mais porque o impacto na vida das pessoas da Organização Mundial do Comércio, do Banco Mundial e do Fundo Monetário Internacional nunca foi maior. É difícil aplicar-lhes os conceitos de democracia desenvolvidos em nível nacional, tendo em vista que os seus "eleitores" são seus Estados membros ou, mais precisamente, os ministérios pertinentes desses Estados.

O Centro para Estudos Globais da Universidade de Victoria levou a cabo, recentemente, uma pesquisa sobre as "melhores práticas" para aumentar a transparência, a participação e a accountability nas organizações internacionais ${ }^{13}$. O grau de inovação é impressionante, mas assim também é o grau de descontentamento da sociedade civil, conforme manifestado nas continuadas séries de demonstrações antiglobalização. As críticas mais freqüentemente repetidas são de que é a agenda corporativa que predomina, e que os governos negligenciaram a sua responsabilidade em moldar a 
globalização de forma que um número suficiente de pessoas se beneficiasse e o meio ambiente não fosse devastado.

Essas preocupações sobre prioridades corporativas e o papel do governo são importantes e precisam ser tratadas. Afinal é por meio de governos eleitos que os cidadãos terão oportunidade de fazer mais para moldar a globalização. As vozes da sociedade civil ouvidas pelas ONGs são importantes, mas não suficientes em si.

As instituições internacionais estão em situação particularmente difícil. Seus constituintes são os governos nacionais - de fato, departamentos específicos dos governos nacionais. As instituições internacionais devem responder, e de fato respondem, a esses constituintes. Porém, isso não acontece por meio de processo transparente que esteja aberto à sociedade civil. O mais frustrante ainda é que o processo, às vezes, é mais aberto a empresas do que à sociedade civil. Isso é um problema. Como conseqüência da revolução da informação e das comunicações, agora é mais fácil para os cidadãos saberem o que está acontecendo e para grupos ou indivíduos trabalharem uns com os outros de maneira estratégica ou até mesmo tática. Eles estão atentos e podem responder a determinado problema detectado.

O “encolhimento do papel” do Estado não está, porém, próximo. Os Estados continuam sendo os atores-chave em negociações e instituições internacionais ${ }^{14}$. O que mudou é que os Estados e, portanto, seus altos dirigentes precisam operar de modos significativamente diferentes. Eles precisam estar preparados para compartilhar o palco. Precisam trabalhar com outros tipos de atores. Isso requererá gama extensiva de novos conhecimentos como também destreza por parte dos altos dirigentes.

\section{Desafios da globalização para a gestão pública}

Não há dúvida de que um número significativo de pessoas tem reservas quanto à globalização. Existem muitas pessoas sendo deixadas para trás. Há muitas pessoas que se sentem excluídas. Mais pessoas precisam ser beneficiadas. O meio ambiente precisa ser protegido. Assuntos de paz e segurança precisam ser priorizados nas agendas. Mesmo um tão comprometido "capitalista" como George Soros disse que os mercados não podem prover bens públicos globais, como proteger o meio ambiente e garantir a segurança. Tem de haver governança em nível global que gerencie desafios em nível global e que ajude a proteger os interesses daqueles que não podem defender-se por si mesmos. Precisa haver convicção de que outras vozes serão ouvidas. 
Foi muito comentado que, na Reunião do Milênio 2000 das Nações Unidas, os líderes dos países mais pobres no mundo não pediram para que a globalização fosse interrompida ou revertida, como muitos protestantes vinham defendendo. Ao invés, esses países defenderam melhor formatação da globalização, melhor gestão dos assuntos globais ${ }^{15}$. The New York Times publicou há pouco longo artigo sobre globalização, que enfatiza que não é mais o comércio que aflige o mundo pobre, mas o "sistema manipulado" que administra o comércio ${ }^{16}$.

Há risco de que a recente inundação de fracassos da governança corporativa nos Estados Unidos alimentará os apetites dos verdadeiros protestantes antiglobalização. A alegação de que os interesses corporativos prevaleciam na agenda global já havia sido feita e os governos faltaram com habilidade ou vontade para desempenhar seu apropriado papel. Agora, o que as pessoas estão aprendendo sobre Enron, Worldcom, e Arthur Andersen, para citar alguns nomes, pode bem botar lenha na fogueira da oposição à globalização. A governança corporativa e a responsabilidade social serão cada vez mais minuciosamente examinadas.

Isso apresenta grandes desafios à gestão pública. A essência das políticas públicas é complexa, os assuntos são interligados, as políticas são difíceis de serem explicadas ao público. No topo disso, está acontecendo importante fragmentação do poder - desde os níveis mais altos de governança nas organizações internacionais até (supostamente) os níveis subordinados do governo que demandam ordens, na sociedade civil e no setor privado ${ }^{17}$. Tudo isso é ainda pior por ter acontecido tanta coisa ao mesmo tempo, conduzindo a complexidade aparentemente insuperável. Isso cria problemas enormes para países em desenvolvimento e, particularmente, mas não somente, para países menores.

Não obstante, na maioria dos governos, se não em todos, os "cartolas" perduram. Por "cartolas" quero dizer que departamentos de governo em particular (por vezes até coordenações dos departamentos) operam como se fossem feudos individuais. As batalhas persistem. A gestão horizontal de assuntos é árdua.

Muitas pessoas não reconhecem que essa fragmentação em nível nacional acarreta sérias implicações em nível internacional. A OMC é "propriedade" dos Ministérios do Comércio. O Programa das Nações Unidas para o Meio Ambiente é "propriedade" dos Ministérios do Meio Ambiente. O FMI e o Banco Mundial são "propriedades” dos Tesouros Nacionais. Em Roma, a Organização das Nações Unidas para a Agricultura e a Alimentação (FAO) é "propriedade" dos Ministérios da Agricultura e o Programa Mundial de Alimentos (WFP), das agências de ajuda entre os doadores. O resultado é que a FAO não consegue desenvolver programas assistenciais e o WFP não consegue promover o desenvolvimento agrícola, e ainda os dois são interdependentes, se não intercambiáveis ${ }^{18}$. Mas a culpa pela falta 
resultante de coordenação não pode ser creditada às organizações internacionais. Ela tem raízes mais profundas. Os governos normalmente não falam com uma única voz, exceto quando ela é do chefe de governo, e ele ou ela não pode estar em todo lugar.

Embora o processo decisório possa ser relativamente direto no nitidamente focado FMI, não quer dizer que ele seja necessariamente bom ou equilibrado ${ }^{19}$. O bom processo decisório é difícil, até para as nações mais desenvolvidas, já que ele envolve o equilíbrio de grande número de objetivos conflitantes. Estabelecer prioridades e categorizá-las é difícil. As pressões são enormes. Em países em desenvolvimento, há uma séria fadiga nas negociações internacionais. Há recursos inadequados no Sul para cobrir todas as várias negociações de importância - variando de mudanças climáticas à $\mathrm{OMC}^{20}$. O resultado, na maioria das vezes, é um "sistema manipulado", como mencionado anteriormente.

Complicações também se originam da necessidade de horizontes de maior prazo, em se tratando de diversos desafios globais. "Dor a curto prazo para ganhos de longo prazo" não é um bom slogan eleitoral, contudo reflete precisamente a realidade para enfrentar um assunto como a mudança climática ${ }^{21}$. A complexidade de assuntos interligados faz sua resolução ainda mais complicada. Agir contra a mudança climática não pode estar dissociado da necessidade de diminuir as diferenças que separam ricos e pobres no mundo.

Melhorar a governança entrou claramente na agenda do desenvolvimento. Mark Malloch Brown, do PNUD, declarou recentemente que $60 \%$ dos recursos daquela organização estão sendo totalmente dedicados à governança.

As demandas sobre os níveis gerenciais nunca foram maiores. Embora tenha-se tentado nos níveis superiores da administração, não é possível separar o desenvolvimento de políticas da gestão. Eles precisam estar unidos. Esses são trabalhos de alta tensão - que exigem tanto fisica como intelectualmente. Dados esses ambientes e os desafios que produz, o que pode ser feito para ajudar os servidores nos níveis superiores?

\section{Necessidades de capacitação e oportunidades}

É preciso haver claramente uma abordagem inovadora da capacitação de alto nível. De fato, a própria palavra "capacitação" pode ser impecílio à obtenção da participação dos níveis gerenciais - algo como "workshop sobre políticas" poderia ser melhor ${ }^{22}$. O primeiro desafio é conseguir que as pessoas venham, participem dos programas oferecidos. Isso se choca com a infeliz realidade de que o urgente sempre parece 
deixar de lado o importante. Muitos (a maioria?) dos gerentes ou não acreditam que precisam da capacitação dos eventos para os quais não têm tempo, ou têm dúvidas sobre a relevância e pertinência dos cursos de capacitação oferecidos.

Parece que os níveis gerenciais no setor privado estão muito mais convencidos da utilidade de se capacitarem. Eles certamente gastam mais tempo nisso. No governo com gerentes há mais um senso de estado de cerceamento, que, se eles não se capacitarem, muito pode dar errado.

O que, então, faz mais sentido são cursos curtos e altamente focados. É importante construir programas de capacitação usando princípios de educação para adultos, como: basear-se na experiência do treinando, trabalhar em grupo, fazer uso de uma variedade de abordagens de ensino e aprendizagem somada ao modelo de palestras e desenhar os programas com flexibilidade para aceitar modificações e mudanças.

É importante fazer com que pessoas que tenham vivido experiências contribuam o máximo possível nos cursos ${ }^{23}$. Outros participantes devem estar no mesmo nível, ou quase, tanto para maximizar os benefícios da troca de experiências como para serem mais atraentes aos demais.

A capacitação em liderança efetiva necessita de ligação viva com o mundo da política e da implementação de forma a atrair bons profissionais ao aprendizado e a encurtar o tempo de reação entre o aprendizado e sua aplicação na máquina do Estado ${ }^{24}$.

Há algo muito importante a ser dito sobre o estudo de casos. Casos deveriam descrever situações reais. Grupos de discussão deveriam permitir aos participantes levantar casos de sua própria experiência, que poderiam dividir com os outro durante o curso.

O tempo apropriado (timing) é importante já que certos períodos do ano são mais corridos do que outros. Fins de semana podem se revelar melhores.

Eu proporia cursos em 12 áreas, embora eles pudessem ser obviamente combinados ou separados de vários modos diferentes:

1) estabelecendo o contexto;

2) liderança e gestão da mudança;

3) alfabetização em linguagem econômica e conceitos de negócio;

4) entendendo novos conceitos de governança global;

5) negociação e habilidades na resolução de disputas;

6) diferenças culturais;

7) lidando com a OMC e organismos de comércio regionais;

8) gestão de assuntos horizontais;

9) análise política, desenvolvimento e mapeamento;

10) participação dos cidadãos;

11) habilidades para resolução de problemas;

12) gestão do risco. 
Estabelecendo o contexto é um bom primeiro passo, particularmente em tempos de rápida mudança. Ele requer a cobertura da variedade de desenvolvimentos listados anteriormente. Não se pode dar por certo que os participantes terão como refletir sobre todas as mudanças que estão acontecendo no mundo. Eles não têm tempo. Trabalho interessante foi feito com o estudo de cenários, o que pode ser útil ${ }^{25}$. Cenários devem salientar que o futuro não é completamente determinado ou determinável. Pelo contrário, ele pode e será afetado pelas escolhas feitas, escolhas sobre as quais os gerentes têm considerável influência. A globalização, em amplo sentido, precisa ser claramente entendida, assim como os debates sobre ela.

Liderança e gestão da mudança é de crítica importância. Boa liderança sempre foi necessária e pode ser ensinada a um grau significativo. Mas a liderança precisou de mudanças, enquanto as organizações se tornaram mais horizontais e níveis inferiores tornaram-se mais "fortes". As pessoas precisam entender as razões da mudança. Estabelecimento de objetivos, delegação e accountability são habilidades fundamentais a serem desenvolvidas, assim como é a colaboração encorajadora tanto dentro de departamentos como entre eles. Cada vez mais a liderança também requer atingir as pessoas fora do governo ${ }^{26}$.

Alfabetização em linguagem econômica e conceitos de negócio é uma exigência fundamental. Alguns gerentes possuem essa habilidade como resultado de treinamentos anteriores e de sua experiência, mas muitos tipicamente não a possuem. Política econômica não pode ser relegada aos "experts" ou àqueles que se percebem exclusivamente responsáveis. Um gerente em um ministério social precisa ser capaz de falar com seus colegas do Ministério da Fazenda ou com representantes do FMI. Ele ou ela precisa ser capaz de explicar a contribuição que o seu ministério pode promover e como fazer novas alianças, evitando ter papel constantemente negativo ou assim ser percebido. Dada a importância dos mercados, das exportações e do investimento, os gerentes precisam entender o que conduz o comércio e o fluxo das finanças privadas. Outra dimensão poderia ser transformar os conceitos de demonstrar resultados do setor privado para a "questão" do desenvolvimento. Há pouquíssima pesquisa ou compartilhamento de aprendizado sobre como chegar a uma abordagem de resultados correta - identificando resultados de missão crítica e indicadores apropriados ${ }^{27}$.

É importante que gerentes entendam novos conceitos de governança global e a existência de outros atores além dos governos. É realmente importante que tais servidores sejam capazes de negociar e até mesmo projetar novas formas de governança que melhor atendam às necessidades de seus países. Os interesses de países em desenvolvimento são imensamente dependentes dos tipos de regimes que estão sendo construídos internacionalmente, e é vital que eles sejam refletidos no processo de construção. O papel do direito internacional e de outras formas 
de estabelecimento de regras precisa ser entendido. Gerentes precisam saber relacionar-se com o mundo dos negócios e com as ONGs. O gerenciamento de novas formas de parcerias com esses atores não estatais requer perspectiva e habilidades da gestão pública tradicional diferentes. É essencial que essas parcerias obtenham sucesso, mas elas levantam desafios como, por exemplo, assegurar a accountability.

Negociação e habilidades de resolução de disputas é algo que pode ser ensinado. Isso inclui a habilidade para cruzar barreiras lingüísticas e culturais. Países em desenvolvimento individuais não terão provavelmente o número de negociadores capacitados que se deseja, mas precisam de negociadores de qualidade. Há habilidades particulares no campo da negociação multilateral, que, se empregadas, poderiam aumentar significativamente a influência de negociadores do Sul. Técnicas de resolução de disputas têm avançado consideravelmente durante as últimas décadas e poderiam ser de grande valia para os gerentes nos programas de capacitação.

A importância de entender diferenças culturais não é freqüentemente compreendida. Tomemos como exemplo a fotografia de Michel Camdessus, ex diretor-geral do FMI, de braços cruzados em frente ao presidente Suharto, da Indonésia. A mensagem que a fotografia transmitiu aos indonésios, à luz de sua cultura, foi de uma força superior exercendo total domínio sobre um inferior, exigindo submissão, neste caso, de seu presidente. Quando o então vice-presidente Nixon chegou à América Central, ele fez um sinal de "o.k." (fazendo um círculo com os dedos polegar e indicador e os outros três dedos para cima). Ele foi severamente vaiado. Era isso antiamericanismo? Não, isso significou para aqueles que esperavam para cumprimentá-lo o que poderia ser descrito como "vão se dar mal"28. Esses podem parecer exemplos triviais, mas ajudam a demonstrar que, para uma negociação próspera, deve haver boa compreensão entre as diversas culturas.

As regras que regulam o comércio têm aplicação cada vez mais ampla. Lidar com a OMC e organismos de comércio regionais não pode ser relegado aos técnicos de comércio. As regras podem parecer (e podem ser) enigmáticas, mas precisam ser muito bem entendidas, e por mais pessoas. O impacto do comércio na cultura e na política social é imenso. É vital que os gerentes mais graduados estejam familiarizados, e realmente saibam lidar, com essa área de desafio global.

Deve haver consideração séria sobre a gestão de assuntos horizontais, incluindo o papel de agências centrais e ministérios principais. Ambos podem ser estruturados de vários modos diferentes. Há perguntas sobre que nível a gestão deveria ocorrer, como se trata de accountability e se faz sentido empreender a reorganização do governo.

Análise política e desenvolvimento é algo que os gerentes não farão eles próprios, mas devem estar atentos ao que é requerido e ser 
capazes de selecionar, treinar e motivar seus colegas em níveis iniciais da carreira. Há uma nova abordagem chamada mapeamento, que está sendo desenvolvida em vários lugares, incluindo o Centro para Estudos Globais (Centre for Global Studies) ${ }^{29}$. Isso leva como seu ponto de partida a que até mesmo a proposta de política mais bem formulada não necessariamente alcança o objetivo. O mapeamento envolve a inclusão de avaliação inter alia de quem tomará a última decisão, qual é o cronograma, quem e o que provavelmente terão maior impacto e que pressões podem ocorrer para afetar o processo. Esse é um processo muito pragmático.

Atores não estatais são claramente de importância crescente. Novas maneiras precisam ser encontradas para aumentar significativamente $a$ participação dos cidadãos. Isso pode ser visto com a reação, na África, ao NEPAD (The New Partnership for Africa's Development). Não é mais adequado para os líderes anunciarem estratégia nova de desenvolvimento. A investigação da opinião pública sobre determinado assunto, grupos focais, reuniões de comunidade e outras técnicas inovadoras precisam ser encontradas. Maneiras imaginativas de descrever as escolhas políticas são necessárias. A participação não deveria acontecer somente após o governo ter tomado a decisão sobre seu planejado curso. Note que não focalizei as ONGs, cujo número, em nível internacional e nos países meridionais, está aumentando dramaticamente ${ }^{30}$. Elas podem desempenhar papel significante, mas não suficiente. O que é necessário e não tão óbvio é como engajar os cidadãos comuns nas discussões sobre políticas e programas que terão impacto sobre eles. As suas opiniões podem ou não ser representadas em organizações estabelecidas.

Embora possa soar muito óbvio, não há nada mais importante que habilidades para resolução de problemas. Em grau significativo, elas podem ser aprendidas. Tenho sido perguntado freqüentemente se poderia dizer alguma coisa sobre o que conduziu a minha carreira relativamente próspera no governo. Concluí que foi acima de tudo uma qualidade, ou pelo menos assim me foi dito por meus chefes - a capacidade para resolver problemas. Isso leva a pessoa para a área de relações interpessoais efetivas e além. Envolve a necessidade de pensar com os dois hemisférios cerebrais assim como "pensar livre de barreiras", em outras palavras, pensar não convencionalmente.

Gestão do risco sempre foi requerida dos gerentes, mas nunca tanto como hoje. Há uma tendência natural de ser avesso ao risco quando no governo. Mas isso pode conduzir, na pior das hipóteses, à paralisia e, menos danosa mas ainda infeliz, à perda de oportunidades importantes. Se se pensar nos desafios que estão por vir no campo de biotecnologia, fica claro que os gerentes ao redor do mundo precisam ser capazes de confiar nas técnicas mais sofisticadas de avaliação de risco. Os benefícios potenciais em termos de segurança alimentar e saúde são enormes, mas há 
riscos inquestionáveis. As escolhas que precisam ser feitas são extremamente políticas, mas precisam estar baseadas no grau máximo da análise de risco e das técnicas de gestão.

A capacitação sobre a integração de prioridades políticas com alocação de recursos poderia também ser oferecida de diferentes maneiras. Uma coisa é o que o governo diz que quer fazer. Outra é levar isso a cabo de fato. Orçamentos tendem a ser redigidos de baixo para cima. Cortes são feitos freqüentemente de cima para baixo. Nem o processo está necessariamente relacionado às prioridades políticas do governo.

Habilidades de comunicação de gerentes são freqüentemente deficientes. Não funciona delegar ao "Departamento de Comunicação" como explicar ao público o que foi decidido. Apoio precisa ser mobilizado de uma comunidade grande. Estratégias são necessárias para lidar com a falta de percepção e com a confusão. A mídia pode bem compor o problema. $\mathrm{O}$ "processo de moldar" assuntos é crítico e é sobremaneira uma habilidade aprendida $^{31}$. Se os assuntos não estão estruturados corretamente, o resultado é freqüentemente a criação de problemas aparentemente insuperáveis de comunicação.

\section{Uma idéia adicional}

Este artigo tratou das mudanças que estão ocorrendo no mundo para estabelecer o contexto para o tipo de capacitação que seria mais valioso aos gerentes. A capacitação seria suprida essencialmente por cursos de curta duração. Uma outra parte da iniciativa da ONU/IASIA está focalizada nas mudanças necessárias em escolas de política pública, gestão e administração, de forma a capacitar a próxima geração de gerentes. Isso também vale muito a pena.

Há uma idéia intermediária que gostaria de ver discutida. Ela envolveria apoio à criação de programas de certificação para "Mestres de Gestão Pública Global”. Esses programas seriam para pessoas, em estágio médio de suas carreiras, que estão ou estarão envolvidas ou lidam com organizações internacionais, negociações e outras formas de governança global. Pouquíssimas escolas existentes fazem isso. É uma lacuna séria.

A melhor abordagem seria seguir aquela aplicada pela Royal Roads University (em Victoria, Canadá), entre outras ${ }^{32}$. Três ou quatro residências semanais, uma vez por ano, durante dois anos, são combinadas com educação a distância pela internet. Isto torna a capacitação bastante exequíivel para os "aprendizes" (não são chamados de estudantes) cumprirem as responsabilidades de suas posições, enquanto obtêm as habilidades de que precisarão nas próximas fases de suas carreiras. 
1 David Held e Anthony McGrew, David Goldblatt e Jonathan Perraton. Global transformations. Stanford: Stanford University Press, 1999. Held é o mais importante pensador que escreve, nos dias de hoje, sobre a amplitude de assuntos em relação à globalização. Ele também os põe em perspectiva histórica.

2 P. J. Simmons destacou esses pontos a mim, e eu os aprecio.

3 Nota do tradutor - Neologismo referente aos simultâneos processos de fragmentação e integração, formado dos vocábulos da língua inglesa fragmentation e integration.

4 Rosenau descreve esse fenômeno em virtualmente tudo o que escreveu na última década. Sua conceitualização das mudanças no sistema internacional é sem igual.

5 Ibid.

6 Ibid.

7 Agradeço a Elizabeth McAllister do Banco Mundial por fazer essa observação.

8 Para informação adicional, veja Gordon S. Smith e Moises Naim, Altered States. Ottawa: International Development Research Centre, 2000.

9 P. J. Simmons e Chantal Jonge Oudraat. Managing global issues. Washington: Carnegie Endowment for International Peace, 2001.

${ }^{10}$ David Held et al. Ibid. O argumento de Held e seus colegas é demasiado otimista, em minha opinião. Richard Falk também escreveu sobre esse assunto.

${ }^{11}$ Wolfgang Reinicke. Critical choices. Ottawa: International Development Research Centre, 2000. Veja também o trabalho de Anne-Marie Slaughter.

${ }^{12}$ United Nations Development Program. Human development report 2002. Nova York: PNUD, 2002.

${ }^{13}$ The Centre for Global Studies. "Rethinking governance" handbook. Victoria: University of Victoria, 2001.

${ }^{14}$ Gordon Smith e Daniel Wolfish (Eds.). Who is afraid of the State? Toronto: Univeristy of Toronto Press, 2001.

${ }^{15}$ Sou grato à vice-secretária-geral da ONU Louise Frechette, que enfatizou esse ponto.

${ }^{16}$ The New York Times Magazine, August 18,2002; artigo escrito por Tina Rosenberg.

${ }^{17}$ Veja Smith e Wolfish, op. cit.

${ }^{18}$ Meus agradecimentos a Jeremy Kinsman por mostrar os problemas em Roma como excelente exemplo do que quero dizer.

${ }^{19}$ Joseph Stiglitz não esconde seus sentimentos sobre esse assunto em seu recente livro, Globalization and its discontents. New York: Norton, 2002.

${ }^{20}$ Adil Najam da Universidade de Boston é autoridade sobre esse assunto, com capacidade impressionante para combinar análise persuasiva e humor.

${ }^{21}$ David Victor e eu temos um capítulo que trata desse assunto em livro que será editado por Harold Coward e Andrew Weaver e publicado pela editora da Sir Wilfrid Laurier University.

${ }^{22}$ Meus agradecimentos a Budd Hall, decano de Educação na Universidade de Victoria, por fazer essa e outras sugestões.

${ }^{23}$ Shirley Walters (Ed.). Globalization, adult education and training. Londres: Zed Books, 1997.

${ }^{24}$ Elizabeth McAllister reforçou a importância desse ponto.

${ }^{25} \mathrm{O}$ trabalho da Shell International tem sido líder nessa área durante anos. Tenho apreciado as recomendações de Ged Davis, da Shell. Ele fez um comentário sobre a primeira versão 
desse artigo: "a experiência da construção e de uso de cenários é que aqueles que aprendem mais são aqueles que constróem cenários e que a sua utilização é intensificada quando os treinandos estiverem mais aptos a claramente visualizar diferentes futuros possíveis".

${ }^{26}$ Tony Campbell, que teve a experiência de lecionar vários desses assuntos, argumenta que liderança e gestão da mudança deveriam ser ensinados separadamente - ele tem um bom argumento.

${ }^{27}$ Meus agradecimentos novamente a Elizabeth McAllister.

${ }^{28}$ P. 76. Howard Richler. Take my words (Vancouver: Ronsdale Press, 1996). Na Alemanha, Nixon não se sairia melhor; esse gesto seria entendido como "seus imbecis".

${ }^{29}$ Terry Smutylo. Outcome mapping. Ottawa: International Development Research Centre, 2002. Abordagens análogas do processo de decisão sistemática existem no contexto do serviço público. Por exemplo, "Policy analysis in government", que pode ser encontrado no site do governo canadense: http://learnet.gc.ca/eng/lrncentr/online/policy. htm\#Four\%20Major\%20Steps. O "Decision process guidebook" do Departamento do Interior de Recuperação dos EUA (US Dept. of the Interior Bureau of Reclamation) é outro exemplo de abordagem sistemática de como influenciar as decisões no governo. Esse guia utiliza um modelo-padrão de dez passos chamado "Decision process worksheet". www.usbr.gov/Decision-Process/.

${ }^{30}$ Ann Florini, agora na Brookings Institution, fez alguns excelentes trabalhos nessa área. Veja seu livro The third force: the rise of transnational civil society. Washington: Carnegie Endowment for International Peace, 2000.

${ }^{31}$ Veja o excelente estudo, dirigido por Princeton Lyman, From values to advocacy. Washington: The Aspen Institute, 2002. A conclusão é que o que é envolvido em uma comunicação de sucesso é muito mais do que apresentar bem os fatos. O público tem, implícita ou explicitamente, pontos de referência, maneiras de organizar os fatos. A boa comunicação freqüentemente tem de mudar o ponto de referência em primeiro lugar.

${ }^{32}$ Veja www.royalroads.ca. 


\section{Novos desafios para a capacitação de liderança de alto nível na gestão pública e governança em um mundo globalizante}

Gordon S. Smith

Este artigo aborda as mudanças econômicas, sociais, ambientais e comportamentais que estão ocorrendo no planeta, visando a estabelecer um contexto que sirva de base para o tipo de capacitação mais adequado para os níveis gerenciais de governo. A partir de três fatores interdependentes - globalização, difusão da democracia e impactos na governança — é proposta uma estrutura de capacitação, focalizando 12 diferentes áreas.

\section{Nuevos desafíos para la capacitación de liderazgo de alto nivel en la gestión pública y gobernanza en un mundo globalizante \\ Gordon S. Smith}

Este artículo aborda los cambios económicos, sociales, ambientales y de comportamiento que están ocurriendo en el planeta, con vistas a establecer un contexto que sirva como base para el tipo de capacitación más adecuado para los niveles administrativos de gobierno. A partir de tres factores interdependientes - globalización, difusión de la democracia e impactos en la gobernanza - es propuesta una estructura de capacitación, enfocando 12 áreas diferentes.

\section{New challenges for high level leadership training in public management and governance in a globalizing world}

\section{Gordon S. Smith}

This article addresses economic, social, environmental, and behavioral changes taking place on the planet with the aim of defining a context that may be used as a basis for a more appropriate training for government managers at different levels. Based on three interdependent factors - globalization, dissemination of democracy, and impacts on governance - a training framework focused on 12 different areas is proposed.
Revista do

Serviço

Público

Ano 54

Número 2

Abr-Jun 2003

Gordon S.

Smith é PhD em ciência política pelo Massachusetts Institute of Technology (MIT), diretor do Centre for Global Studies e professor adjunto de ciência política na Universidade de Victoria, Canadá.

Contato: gordonssmith @ shaw.ca 


Nacional de Administração Pública, voltada para a divulgação e debate de temas relacionados ao Estado, à administração pública e à gestão governamental. Procurando o aprimoramento permanente da revista, tanto no seu conteúdo quanto na apresentação gráfica, pedimos aos nossos colaboradores a observação das normas abaixo descritas.

\section{Normas para os colaboradores}

1. Artigos: sempre inéditos no Brasil, devem conter de 20 a 30 laudas de 20 linhas de 70 toques, devendo vir acompanhados de um resumo analítico em português, espanhol e inglês,de cerca de 150 palavras, que permita uma visão global e antecipada do assunto tratado.

2. Ensaios: devem ser inéditos no Brasil e ter entre 6 e 10 laudas em espaço duplo com 20 linhas de 70 toques.

3. Resenhas de livros: devem ser originais e não excederem a 4 laudas em espaço duplo com 20 linhas de 70 toques Devem apresentar, de modo sucinto, a obra, com comentários que situem o leitor na discussão apresentada. As resenhas devem ser enviadas em português, sem notas de rodapé, contendo o título completo e subtítulo do livro, nome completo do autor, local de publicação, editora e ano de publicação.

4. Vinculação institucional: Artigos, ensaios e resenhas devem vir acompanhados de uma breve informação sobre a formação e vinculação institucional do autor (em até duas linhas), acompanhadas do respectivo arquivo digital e e-mail para contato.

- Os originais de todos os trabalhos devem ser encaminhados ao editor em arquivo digital, em programa de uso universal e enviados para editora@enap.gov.br. Usar apenas as formatações-padrão.

- Notas, referências e bibliografia devem vir ao final do trabalho, e não ao pé da página. Notas e referências, sendo o caso, devem vir devidamente numeradas.

- Os trabalhos que se adequarem ao perfil das publicações ENAP serão apreciados pelo conselho editorial, que decidirá sobre a publicação com base em pareceres de consultores ad hoc.

- Os originais enviados à ENAP não serão devolvidos. A ENAP compromete-se a informar os autores sobre a publicação ou não de seus trabalhos.

\section{Editores}

Encaminhem à Revista do Serviço Público exemplares de livros publicados, a fim de que os mesmos possam ser resenhados. Os resenhadores interessados receberão exemplares dos livros enviados. Os originais de todos os trabalhos devem ser encaminhados ao editor em arquivo digital, em formato de uso universal (.doc, .rtf ou .txt) e enviados para editora@enap.gov.br. Usar apenas as formatações-padrão.

Na primeira página do trabalho, devem constar informações sobre formação, vinculação institucional e endereço eletrônico do autor (em até duas linhas).

As citações devem vir no formato "(AUTOR, ano)". Notas e referências bibliográficas devem vir ao final do trabalho e de acordo com as normas da Associação Brasileira de Normas Técnicas (ABNT).

Para maiores informações acesse www.enap.gov.br

ENAP Escola Nacional de Administração Pública

Diretoria de Comunicação e Pesquisa

SAIS Área 2-A Brasília, DF - CEP 70610-900

Tel: (61) 4457102 - Fax: (61) 4457178

E-mail: editora@enap.gov.br 